\title{
Comparison of constraint analyses with global and local approaches under uniaxial and biaxial loadings
}

\author{
Guian Qian $^{\mathrm{b}, *}$, Yupeng $\mathrm{Cao}^{\mathrm{c}}$, Markus Niffenegger ${ }^{\mathrm{a}}$, Yuh J. Chao ${ }^{\mathrm{d}}$, Wenwang $\mathrm{Wu}^{\mathrm{e}, \mathrm{f}}$ \\ ${ }^{a}$ Laboratory for Nuclear Materials, Nuclear Energy and Safety Department, Paul Scherrer Institute, Villigen PSI, 5232, Switzerland \\ b State Key Laboratory for Nonlinear Mechanics (LNM), Institute of Mechanics, Chinese Academy of Sciences, Beijing 100080, China \\ ${ }^{\mathrm{c}}$ Department of Component Research and Design, Shanghai Nuclear Engineering Research and Design Institute, Shanghai 200233, China \\ d Department of Mechanical Engineering, University of South Carolina, Columbia, SC 29208, USA \\ e Institute of Advanced Structure Technology, Beijing Institute of Technology, Beijing 100081, China \\ ${ }^{\mathrm{f}}$ Beijing Key Laboratory of Lightweight Multi-functional Composite Materials and Structures, Beijing 100081, China
}

\section{A R T I C L E I N F O}

\section{Keywords:}

Constraint

Biaxial loading

Cruciform specimen

Local approach to fracture

\begin{abstract}
A B S T R A C T
Fracture toughness is an important material property used to perform the integrity assessment of engineering components containing cracks. Due to the difference in crack tip constraint, specimens may show different fracture toughness. The constraint difference for cruciform specimen with shallow crack, compact tension (CT) specimen and three point bending specimen with shallow and deep cracks are investigated. Both linear elastic and elastic-plastic fracture mechanics are applied to study the constraint effect based on two-parameter fracture criterion. Crack tip constraint depends on the applied loading. $\mathrm{J}-\mathrm{A}_{2}$ method is used to precisely capture the crack tip constraint and crack tip stress distributions. Local approach to fracture can be applied to transfer the fracture toughness among different specimens under uniaxial and biaxial loadings. In case of positive $\mathrm{T}_{\text {-stress}}, \mathrm{T}_{\text {-stress }}$ increases with $\mathrm{K}_{\mathrm{I}}$. In the case of negative $\mathrm{T}_{\text {-stress }}$, $\mathrm{T}_{\text {-stress }}$ decreases with $\mathrm{K}_{\mathrm{I}}$. $\mathrm{Q}_{\text {-stress }}$ generally decreases with applied loading for both deep crack and shallow crack cases. Loss of constraint occurs for the single-edged bending (SEB) specimen with deep crack and thus raises the question whether the SEB specimen is proper to be used to obtain material toughness. For the cruciform bending (CRB) specimen, the constraint at the crack tip surface shows a least constraint while the deepest point has a relatively higher constraint. At a fracture probability of $10 \%$, the fracture toughness difference between CT specimen and CRB specimen is about $50 \mathrm{MPa}^{0.5}$, i.e $200 \%$ of the fracture toughness. This big difference demonstrates the importance of considering the constraint effects in the integrity analysis.
\end{abstract}

\section{Introduction}

Fracture toughness is an important material property used to perform the integrity assessment of engineering components containing cracks. Widely used industry standards (e.g. ASTM standard) to test fracture toughness utilize specimens subjected to uniaxial loading, e.g., three point bending and compact tension (CT) specimens in order to obtain a lower bound value of material's fracture toughness (ASTM E399-09e2, 2011). However, a lot of engineering structures are subjected to biaxial/multiaxial loadings. Reactor pressure vessels (RPVs) in nuclear power plants are subject to biaxial loading during pressurized thermal shocks initiated by the loss-of-coolant accidents (Qian and Niffenegger, 2013; Qian et al., 2014). The thermal, pressure and residual stresses in the RPV wall combine to form a biaxial stress state at the crack tip. However, the fracture toughness of materials, $K_{\mathrm{c}}$ or $J_{\mathrm{c}}$, required for the integrity assessment of the RPV is obtained from the conventional deeply-cracked single-edged bending (SEB) and CT specimens tested under uniaxial loading. The crack-tip stress state in specimens (uniaxial), as well as the crack tip constraint is quite different from that of a real crack in RPV (biaxial). For the sake of nuclear safety, it is important to determine accurate fracture toughness for RPV materials or other similar structures. Thus, the question arises whether results obtained from specimens tested in the laboratory can be transferred to actual RPV in nuclear power plants. The difference of constraint effect (in-plane and out-of-plane) in different specimens and structures, as shown in Fig. 1, should be taken into account (Qian and Niffenegger, 2015). There are two options to consider the constraint effect. First option is to test specimens with different constraints, which could be very expensive. Second option is to work out a simple model and procedure to transfer the fracture toughness from standard

\footnotetext{
* Corresponding author.

E-mail addresses: guian.qian@psi.ch (G. Qian), caoyupeng@snerdi.com.cn (Y. Cao).
} 


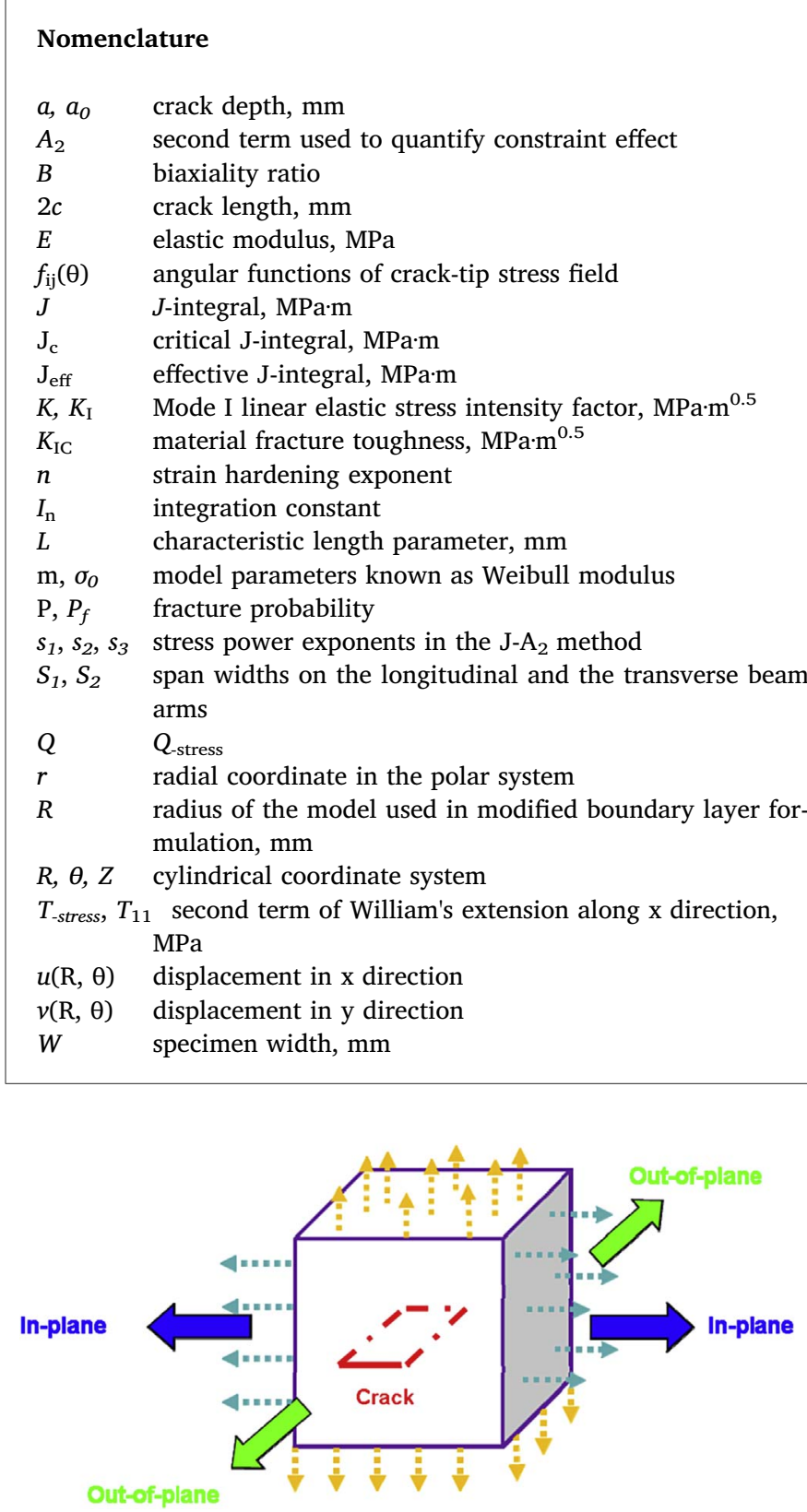

Fig. 1. In-plane and out-of-plane constraints for a 3D crack subjected to biaxial loading.

specimens to real components. Obviously, the second option could be more advantageous considering time, efforts and economic effects and therefore this paper is devoted to this aspect. However, it should be noted that a simple model/procedure alone cannot hold without the support of test data at selected geometries/specimens. In this sense, both options are interacted.

In order to transfer the fracture toughness from standard specimens to real components, the actual constraint of a specific geometry should be analyzed. A second (e.g. J-T, J-Q, J-A ) parameter can be used to quantify the crack-tip constraint of engineering structures in comparison to that of the laboratory specimen. The K-T (or J-T) approach, J-Q theory and $\mathrm{J}-\mathrm{A}_{2}$ are the known theories, where the parameters $\mathrm{T}, \mathrm{Q}$ and $A_{2}$ can be used to quantify the constraint effect on the crack-tip field and fracture toughness. The J-T methodology, developed by Hancock et al. (Hancock and Du, 1991), is used to quantify the in-plane constraint effect on fracture toughness for different crack geometries. However, the $\mathrm{J}-\mathrm{T}$ approach is limited to linear elastic analysis and it becomes less meaningful as the plastic deformation expands arounds $\mathrm{x} \quad$ length along specimen thickness, $\mathrm{mm}$

$\mathrm{V}_{0} \quad$ elementary volume, $\mathrm{mm}^{3}$

$\mathrm{V}_{\mathrm{pl}} \quad$ volume of the plastic deformation zone

$v \quad$ Poisson's ratio

$\alpha \quad$ material coefficient in Ramberg-Osgood relationship

$\sigma_{0} \quad$ yield stress, MPa

$\sigma_{1} \quad$ first principal stress, $\mathrm{MPa}$

$\sigma_{\mathrm{w}} \quad$ Weibull stress, MPa

$\sigma_{\text {th }} \quad$ threshold stress, MPa

$\sigma_{\mathrm{e}} \quad$ von Mises stress, MPa

$\sigma_{\mathrm{ij}} \quad$ stress at crack tip region, MPa

$\widetilde{\sigma}_{i j}{ }^{k}(\theta, n)$ dimensionless functions in the $\mathrm{J}-\mathrm{A}_{2}$ method

$\sigma_{\mathrm{xx}}, \sigma_{\mathrm{yy}}, \sigma_{\mathrm{zz}}$ stress along different directions, MPa

$\left(\sigma_{\theta \theta}\right)_{H R R}$ opening stress in small scale yielding, MPa

$\left(\sigma_{\theta \theta}\right)_{F E A}$ opening stress in a structure, $\mathrm{MPa}$

$\varepsilon_{0} \quad$ yield strain

$\varepsilon \quad$ strain

$\theta$ angular coordinate in the polar system

$\Phi \quad$ angle of elliptical crack

$\delta_{\mathrm{ij}} \quad$ Kronecker delta

CT compact tension

CDF crack driving force

$\mathrm{CRB}$ cruciform bending

FE finite element

FEA finite element analysis

MBL modified boundary layer

MFC material failure curve

PTS pressurized thermal shock

RPV reactor pressure vessel

SEB single-edged bending

SSY small scale yielding the crack tip. Based on the theory of deformation plasticity, the J-Q methodology (actually, it is a numerical solution) is developed based on a series of detailed elastic-plastic finite element (FE) calculations for various geometries (O'Dowd and Shih, 1991). In addition, the J-A $\mathrm{A}_{2}$ solution is developed based on the higher-order, asymptotic expansion of crack-tip field for an elastic-plastic, power-law hardening material (Yang et al., 1993a, 1993b; Chao et al., 1994). A comprehensive review of these methodologies is referred in (Zhu and Joyce, 2012). Furthermore, the effects of out-of-plane constraint have been studied along the thickness of specimens and plenty of efforts have been made in the past decades (Faleskog, 1995; Matvienko et al., 2013; Guo, 1993). In addition to the above-mentioned global approach, the local approaches to (cleavage) fracture (micro mechanics model), which couple macroscopic fracture behavior with micro scale deformations, captures the constraint effect on cleavage due to crack geometry and loading. The most widely used one, proposed by Beremin (1983), is a statistical approach based upon the Weibull stress concept. The advantage of Beremin's model is that model parameters are assumed to be material properties and can be transferred from one specimen geometry or constraint level to another.

In order to experimentally study both in-plane and out-of-plane constraint effects, the cruciform bending specimen (CRB) is designed to approximate the biaxial stresses resulted from realistic engineering loading, as well as to study the influence of biaxial stress on crack-tip constraints. A series of large (4T) cruciform specimen were tested by Bass et al. (1999). while Joyce et al. (2005). developed a medium scale CRB specimens (2T) made of the same steel. In addition, Jörg et al (Hohe et al., 2011). studied that the biaxial effects observed on large scale CRB specimen could be reproduced in the small-scale specimen. It is shown that the biaxial effect may be dependent on material property and detailed stress analysis should be used to characterize the constraints (Link et al., 2007). 
Thus, this paper is devoted to compare crack tip constraints in different specimens and structures, thereby providing hints for transferring material toughness from different specimens to real structures. The biaxial effect on the crack-tip constraint is studied. Different twoparameter approaches, e.g. K-T method, J-Q method and J-A $\mathrm{A}_{2}$ method, are applied to quantify the constraint of a variety of specimens under uniaxial or biaxial loads. The cruciform specimen with a shallow crack, compact tension specimen with a deep crack, and three point bending specimens with shallow and deep cracks are modeled to quantify the constraint effects. Weibull stress and fracture probability according to the local approach to fracture are calculated to compare the constraint difference in the crack tip.

\section{Approaches for constraint analyses}

\section{1. $K$-T method}

The $K$ - $T$ method is generally used for linear elastic in-plane constraint analyses. The $K$ - $T$ concept considers both the first (singular) and second (non-singular) term of the Williams extension (Williams, 1957) of the crack front stress field (in terms of the polar coordinate $r$ and $\varphi$ ):

$\sigma_{i j}=\frac{K_{I}}{\sqrt{2 \pi r}} f_{i j}(\theta)+T \delta_{1 i} \delta_{1 j}$

The $T_{\text {-stress }}\left(T_{11}\right)$ represents the stress acting parallel to the crack plane and is used for in-plane constraint analysis. However, the $T_{\text {-stress }}$ is an elastic parameter and becomes less meaningful as the plastic zone expands at the crack tip. To address this limitation, a new second parameter $\mathrm{Q}\left(\mathrm{Q}_{\text {-stress }}\right)$ was studied for elastic-plastic conditions.

\subsection{J-Q method}

In elastic-plastic analysis, the $\mathrm{Q}_{\text {-stress }}$ is defined by

$Q=\frac{\left(\sigma_{\theta \theta}\right)_{F E A}-\left(\sigma_{\theta \theta}\right)_{H R R}}{\sigma_{0}}$, for $\theta=0, \frac{r \sigma_{0}}{J}=2$

where $\left(\sigma_{\theta \theta}\right)_{F E A}$ is the opening stress in a structure; $\left(\sigma_{\theta \theta}\right)_{H R R}$ represents the opening stress defined from the stress field in small scale yielding (SSY) condition. In general, the parameter Q can effectively describe the constraint effect in the crack-tip stress field for different geometries under a variety of deformation levels. It is a common practice to estimate the $\mathrm{Q}_{\text {-stress }}$ at $\theta=0$ and at the normalized distance $r=2 \mathrm{~J} / \sigma_{0}$. To compute $\left(\sigma_{\theta \theta}\right)_{H R R}$, the modified boundary layer (MBL) model is used.

\section{3. $J-A_{2}$ methodology}

The crack tip stresses in the low constraint geometry gradually deviate from the HRR solution as the load increases. In order to solve this problem, Yang and Chao et al (Yang et al., 1993a, 1993b; Chao et al., 1994). developed asymptotic solutions near a crack tip, which includes several higher order terms. It was demonstrated that the stress, strain and displacement fields can be well characterized by the analytical solution with only three terms, which can be written as

$\frac{\sigma_{i j}}{\sigma_{0}}=A_{1}\left[\left(\frac{r}{L}\right)^{s_{1}} \widetilde{\sigma}_{i j}{ }^{1}(\theta, n)+A_{2}\left(\frac{r}{L}\right)^{s_{2}} \widetilde{\sigma}_{i j}{ }^{2}(\theta, n)+A_{2}{ }^{2}\left(\frac{r}{L}\right)^{s_{3}} \widetilde{\sigma}_{i j}{ }^{3}(\theta, n)\right]$

where the angular functions $\widetilde{\sigma}_{i j}^{k}(\theta, n)(\mathrm{k}=1,2,3)$ are the dimensionless functions of $n$ and $\theta$, the stress power exponents $s_{1}, s_{2}, s_{3}$ $\left(s_{1}<s_{2}<s_{3}\right)$ are only dependent of the hardening exponent $n$, $s_{1}=-\frac{1}{n+1}$ and $s_{3}=2 s_{2}-s_{1}$ for $n>3 . L$ is a characteristic length parameter which can be chosen as the crack length $a$, specimen thickness $W$, or a unit length (e.g., $1 \mathrm{~mm})$. The $(r, \theta)$ represents the local coordinate system established on the plane normal to the crack front with the origin at each point along the crack front. For the HRR field, the parameters $A_{1}$ is given by
$A_{1}=\left(\frac{J}{\alpha \varepsilon_{0} \sigma_{0} I_{n} L}\right)^{-s_{1}}$

$A_{2}$ is an undetermined parameter and is related to the geometry of the specimen and the loading. Hence, similar to $\mathrm{Q}_{\text {-stress }}, A_{2}$ can be used as a quantitative measure of the constraint effect.

\subsection{Beremin model}

As a local approach to fracture, Beremin model (Beremin, 1983) is essentially a two-parameter Weibull distribution as below:

$p=1-\exp \left[-\left(\int_{V_{p l}} \sigma_{1}^{m} d V / V_{0}\right) / \sigma_{0}^{m}\right]=1-\exp \left[-\left(\sigma_{W, \text { Beremin }} / \sigma_{0}\right)^{m}\right]$

with

$\sigma_{W, \text { Beremin }}=\left(\int_{V_{p l}} \sigma_{1}^{m} d V / V_{0}\right)^{1 / m}$

where $\mathrm{P}$ is the cumulative probability of fracture, $\mathrm{V}_{\mathrm{pl}}$ denotes the volume of the plastic deformation zone as the cleavage fracture process zone, $\mathrm{m}$ and $\sigma_{O}$ are the two model parameters known as Weibull modulus and the scale parameter, respectively, $\sigma_{1}$ is the maximum tensile principal stress, $V_{0}$ is an elementary volume representing the mean volume occupied by each micro-crack in a solid, dV is the differential volume.

In order to consider the plastic deformation effect, the cumulative failure probability formulation is modified to adopt a fixed-value threshold stress $\left(\sigma_{\text {th }}\right)$ by Gao et al. (2005),

$P=1-\exp \left[-\left(\frac{\sigma_{W}-\sigma_{t h}}{\sigma_{0}-\sigma_{t h}}\right)^{m}\right]$

\section{Finite element modeling}

In order to compare the crack tip constraints between different experimental specimens, CRB, SEB, CT specimen and MBL model are modeled, as shown in Fig. 2. The geometries of SEB and CT specimen are in agreement with the ASTM standard and the CRB specimen is in line with that used in the international program NESC (Bass et al., 1999). Specimens with different crack depths are considered. The semielliptical crack and through-wall cracks with straight front are modeled. In this way, both in-plane and out-of-plane constraints are included. The sizes of the specimens are listed in Table 1.

A RPV material is studied. The elastic modulus and Poisson's ratio are assumed to be $206 \mathrm{GPa}$ and 0.3 , respectively. The tensile property of the material represented by the Ramberg-Osgood relationship has the form

$\frac{\varepsilon}{\varepsilon_{0}}=\frac{\sigma}{\sigma_{0}}+\alpha\left(\frac{\sigma}{\sigma_{0}}\right)^{n}$

where $\sigma_{0}$ and $\varepsilon_{0}=\sigma_{0} / E$ are the yield stress and the yield strain, respectively, $\alpha$ is a material constant, and $n$ is the strain hardening exponent (with the two coefficients of 1 and 8), as shown in Fig. 3.

3D FE simulations for CRB, CT, SEB specimen and MBL model are conducted by ABAQUS 6.14 (Abaqus 6.14 Manual and Versi, 2017). In order to study the in-plane constraint effect, 3D simulation for SEB specimens with deep and shallow cracks is performed with a/W of 0.5 and 0.1 . Due to symmetry considerations, only one quarter of the specimen (for 3D) is modeled. The displacement is applied on a rigid pin in contact (frictionless) with the specimen and the applied load is obtained from the reaction force acting on the rigid body. Since large strain is expected in the crack tip field, a finite strain (large deformation theory) method is used. Quadrilateral elements and 20-node brick elements (quadratic elements) are used, as shown in Fig. 4. The reduced 


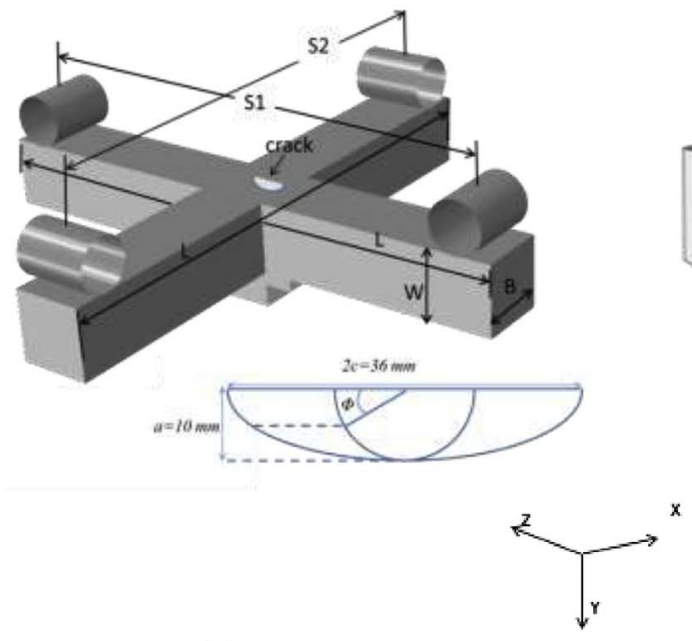

(a)

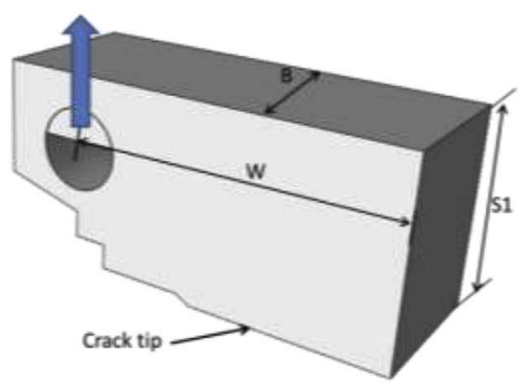
(1)

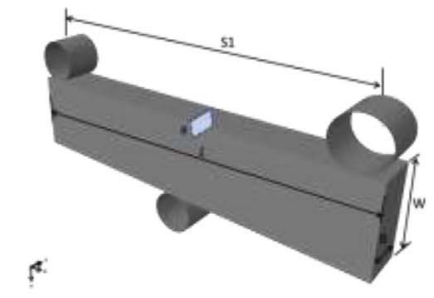

(c)
Fig. 2. Geometry of (a) the CR(B) specimen, (b) CT specimen, (c) SE(B) specimen and (d) MBL model. (b)
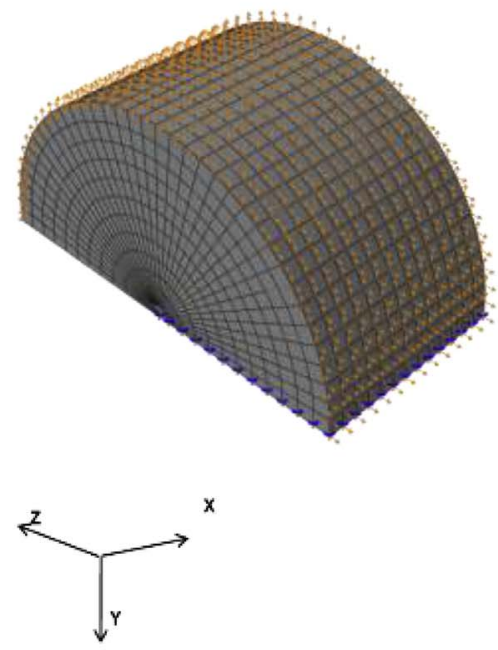

(d)

integration scheme is used in the calculation. The number of elements for CRB, CT, SEB specimen and MBL model are about 105560, 11055, 13822 and 130382, respectively. The deformation contours from FE simulations are shown in Fig. 5.

The J-integral is computed using the domain integral implemented in ABAQUS 6.14, which calculates the J-integral over a predefined number of contours around the crack tip. Under plane strain condition, the SIF calculated from the path-independent J-integral is

$K_{J}=\sqrt{\frac{J E}{1-v^{2}}}$

In order to calculate the Weibull stress according to the local approach to fracture, a subroutine is written to extract the stress and strain distributions for different elements. Fracture probability of each specimen at different loadings is then calculated.

Table 1

Specimens size.

\begin{tabular}{lllllll}
\hline Specimen type & $B(\mathrm{~mm})$ & $W(\mathrm{~mm})$ & $S_{1}(\mathrm{~mm})$ & $S_{2}(\mathrm{~mm})$ & $L(\mathrm{~mm})$ & $a_{0} / \mathrm{W}$ \\
\hline CRB specimen & 104 & 104 & 725 & 725 & 825 & $10 / 104$ \\
CT specimen & 25.4 & 50 & 60 & 80 & 90 & 0.5 \\
SEB specimen & 10 & 20 & 80 & $/$ & 90 & $0.1,0.5$ \\
\hline
\end{tabular}

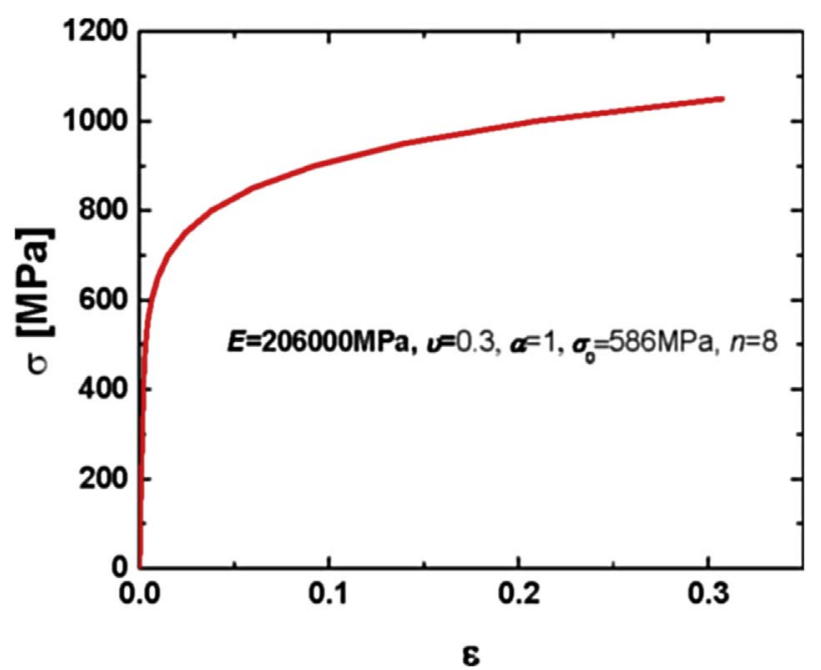

Fig. 3. Relation of stress and strain for the studied material. 


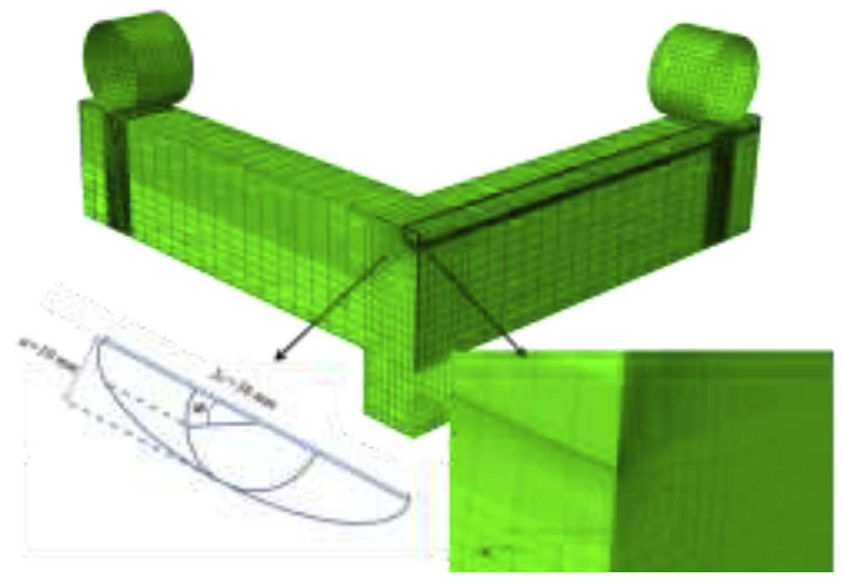

(a)

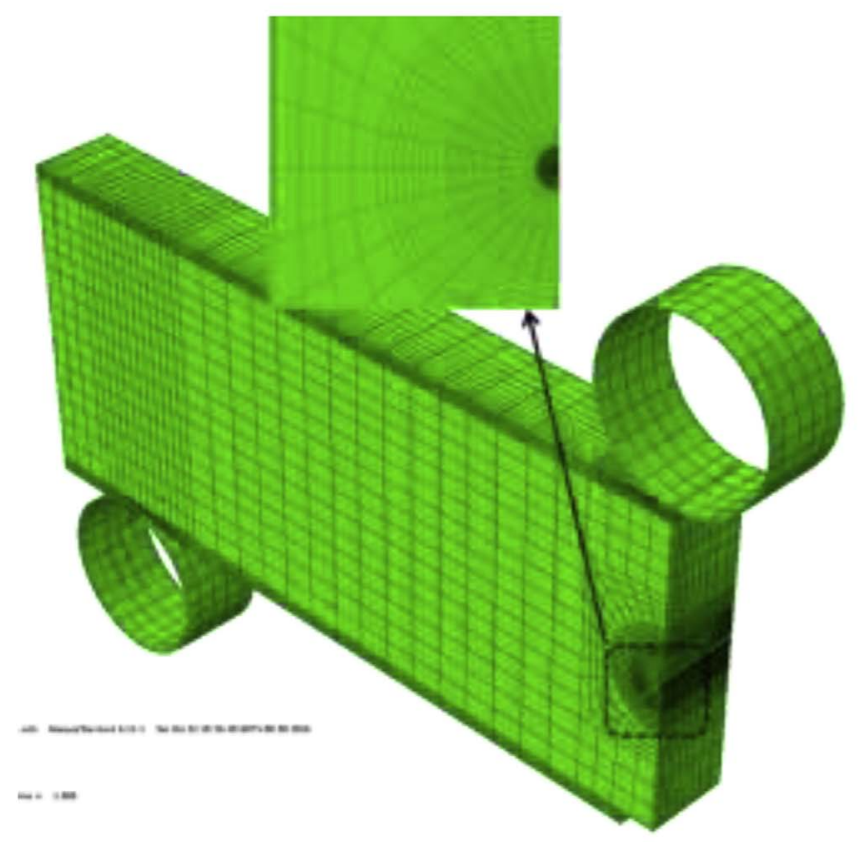

(c)

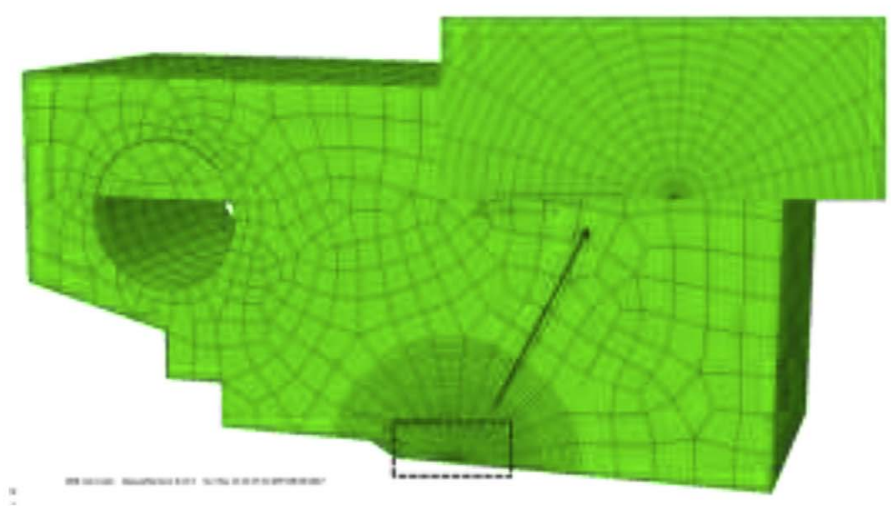

(b)

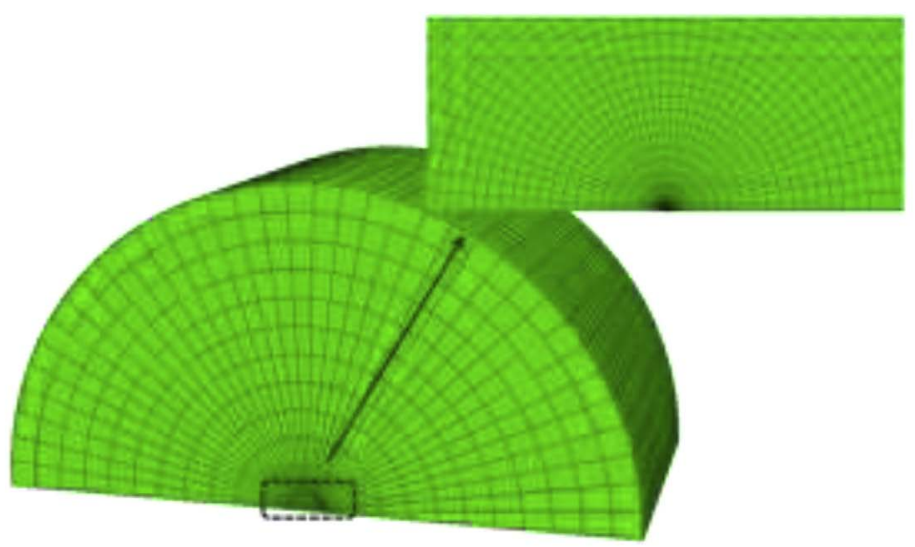

(d)

Fig. 4. FE meshes for (a) CR specimen, (b) CT specimen, (c) SEB specimen and (d) MBL model.

\section{Results}

In the following, K-T method, $\mathrm{J}-\mathrm{Q}$ method, $\mathrm{J}-\mathrm{A}_{2}$ method and the modified Beremin model are applied for the constraint analysis and the results are compared. The cruciform specimen with a shallow crack, compact tension specimen with deep crack, and three point bending specimens with shallow and deep cracks are analyzed.

\subsection{Results from CT specimen}

In the middle plane of the CT specimen, $\mathrm{T}_{\text {-stress }}$ and $\mathrm{Q}_{\text {-stress }}$ distributions with $K_{I}$ and $K_{J}$ are shown in Fig. 6. It is seen that both $T$ and $\mathrm{Q}_{\text {-stress }}$ are positive, indicating that no constraint loss occurs. This confirms the validity of applying CT specimen to obtain the lower bound of material toughness. $\mathrm{T}_{\text {-stress }}$ shows a liner relation with $\mathrm{K}_{\mathrm{I}}$, while $\mathrm{Q}_{\text {-stress }}$ increases with applied loading and then keeps constant.
This means that constraint varies with the applied loading and the elastic constraint is different from elastic-plastic constraint. It is seen in Fig. 6 (a) that with increasing of K, Q-stress keeps almost constant. One possible reason could be due to the large scale yielding with the increasing of $\mathrm{K}$. A similar tendency exists for $\mathrm{A}_{2}$, as referrer in (Chao et al., 1994), which will be discussed later. In order to fully understand the reason, more study is still needed. Using $\mathrm{J}-\mathrm{A}_{2}$ method, the opening stress $\sigma_{\theta \theta}$ in the crack vicinity is plotted in Fig. 6 (b). The opening stress distributions at different loading level $J$ from the $\mathrm{FE}$ analysis are also plotted in Fig. 6 (b). $\mathrm{A}_{2}$ is calculated by substituting $J_{\mathrm{c}}, \sigma_{\theta \theta}$, and $r$ (from FE analysis) into Eq. (3) at each node. The average $A_{2}$ value in the range of $r /\left(J / \sigma_{0}\right)=2-5, \theta=0^{\circ}$ is taken for the specimen. It is seen that the results from FE analysis and $\mathrm{J}-\mathrm{A}_{2}$ method are in good agreement. This indicates that $\mathrm{J}-\mathrm{A}_{2}$ method can be used to precisely capture the crack tip constraint and crack tip stress distributions. It is also shown that $\mathrm{A}_{2}$ is negative and increases with the applied loading. This tendency is in 

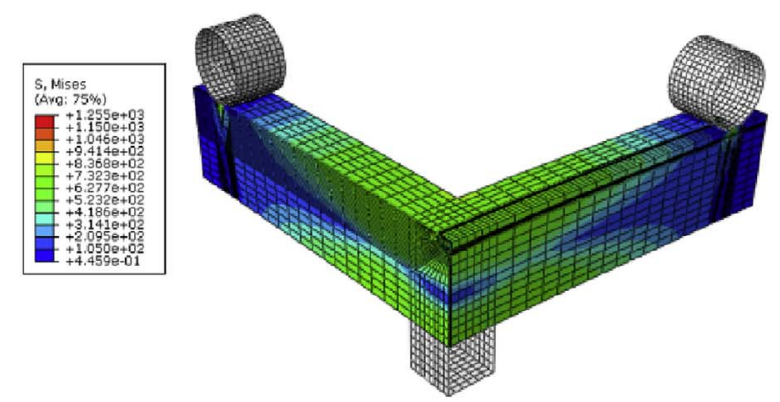

(a)

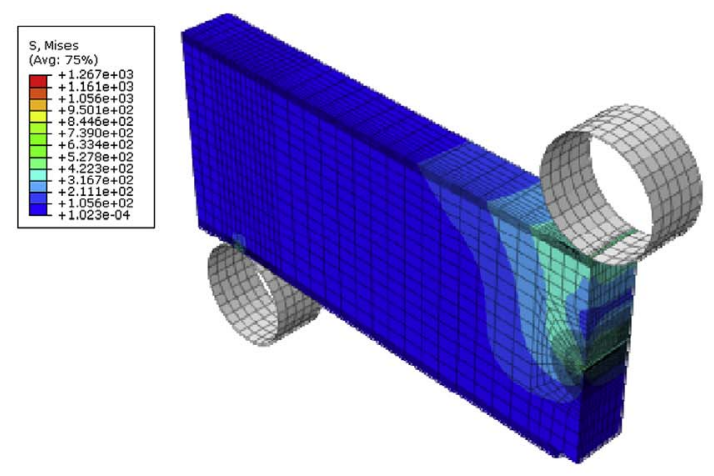

(c)

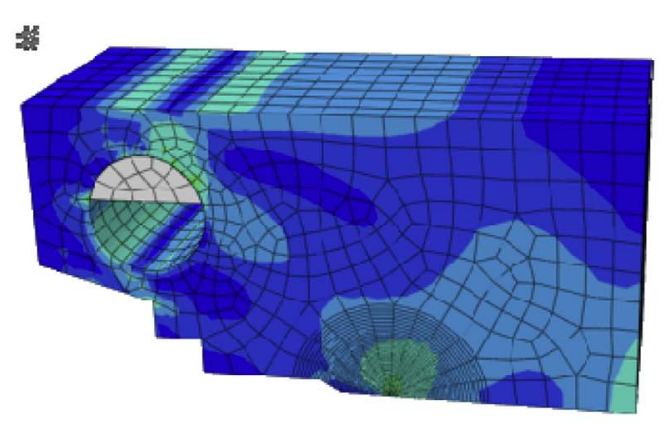

(b)

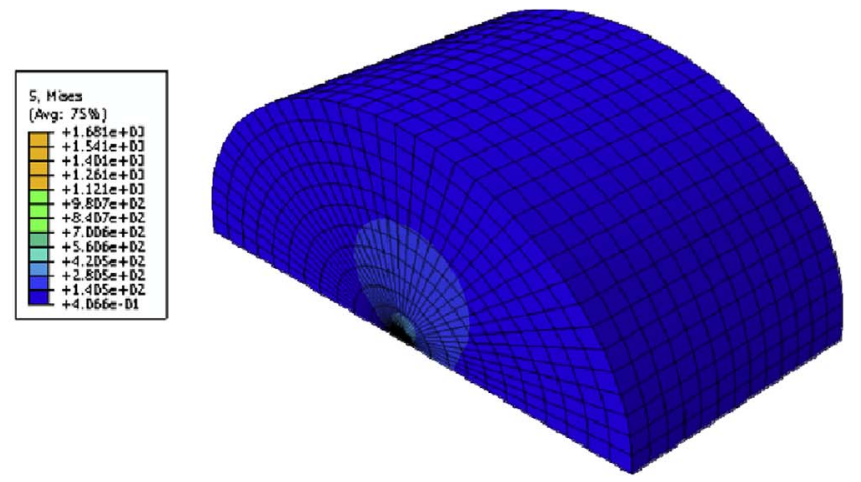

(d)

Fig. 5. Stress distributions for (a) CR specimen, (b) CT specimen, (c) SEB specimen and (d) MBL model.

agreement with $\mathrm{T}_{\text {-stress }}$ but different to $\mathrm{Q}_{\text {-stress }}$.

$\mathrm{J}-\mathrm{A}_{2}$ method is further used to quantify the constraint effect in the elastic-plastic analysis. J-integral increases along the crack front from surface to the deepest point, as shown in Fig. 7. The surface point has a more negative $A_{2}$ than the deepest point, which indicates that the surface point has a lower constraint than the deepest point of the crack front. This is consistent with the common fact that plane stress condition exists on the specimen surface and plane strain condition exists in

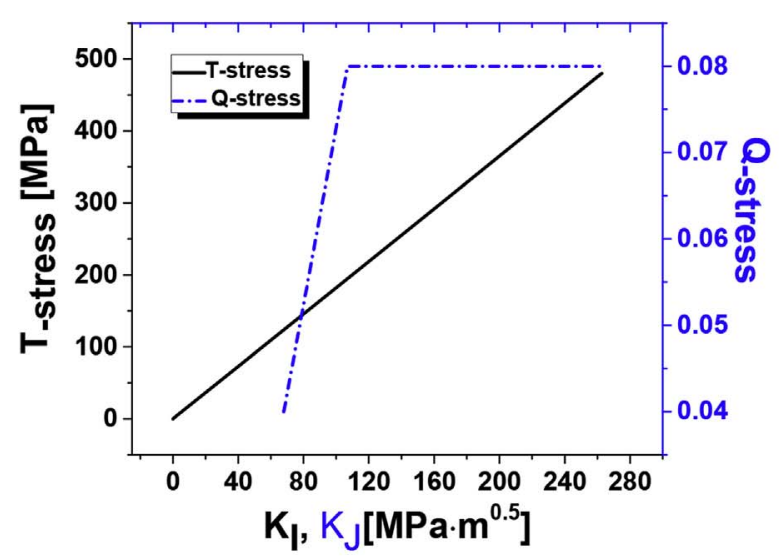

(a) the specimen middle. It should be noted that the negative of $A_{2}$ means the deviation of stress from the HRR solution.

\subsection{Results from SEB specimen}

In the middle plane of the SEB specimen with deep and shallow cracks, $\mathrm{T}_{\text {-stress }}$ vs. $\mathrm{Q}_{\text {-stress }}$ distributions are shown in Fig. 8 (a). It is seen that both $\mathrm{T}_{\text {-stress }}$ and $\mathrm{Q}_{\text {-stress }}$ vary significantly with the applied loading

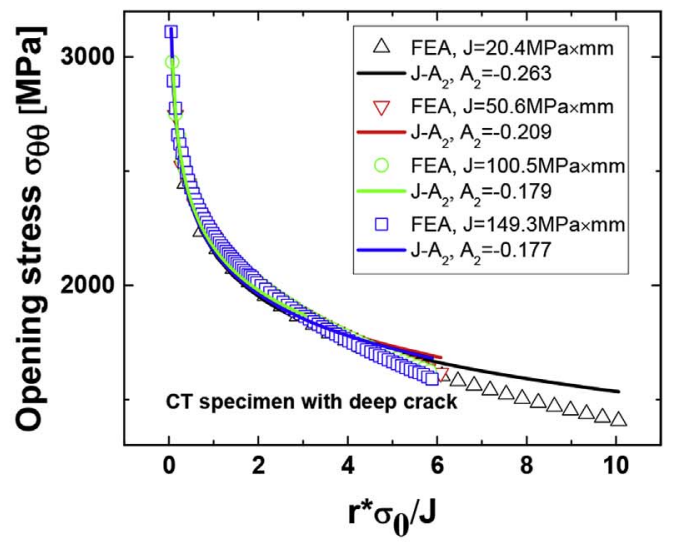

(b)

Fig. 6. (a) $\mathrm{T}_{\text {-stress }}$ and $\mathrm{Q}_{\text {-stress }}$ distributions with $\mathrm{K}_{\mathrm{I}}$ and $\mathrm{K}_{\mathrm{J}}$ for CT specimen, (b) Opening stress distribution in the vicinity of crack tip for CT specimen. 


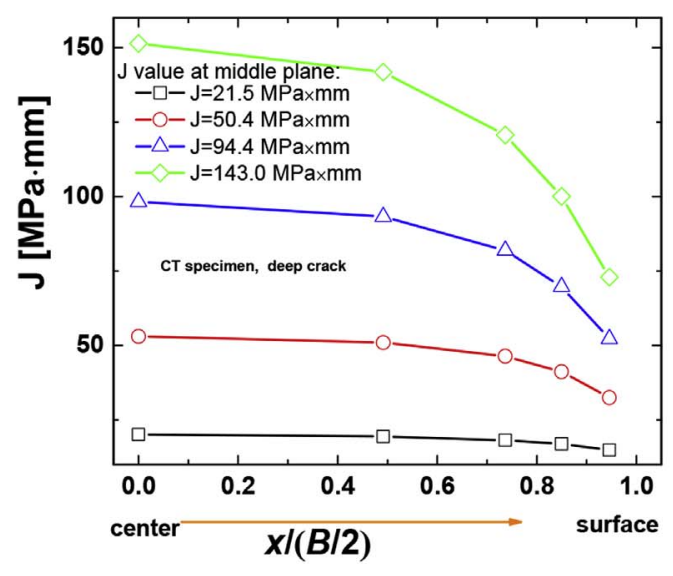

(a)

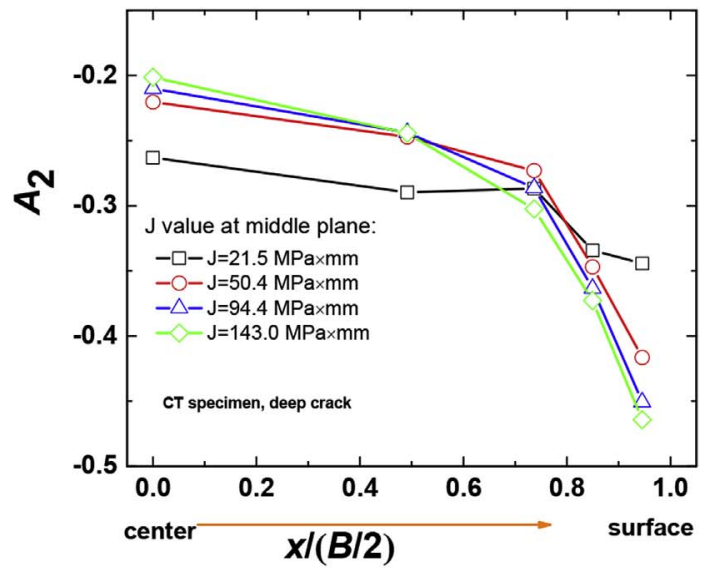

(b)

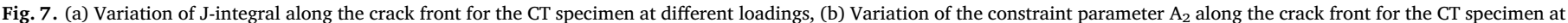
different loadings.

and the crack depth. In case of positive $\mathrm{T}_{\text {-stress }}, \mathrm{T}_{\text {-stress }}$ increases with $\mathrm{K}_{\mathrm{I}}$. In the case of negative $\mathrm{T}_{\text {-stress }}, \mathrm{T}_{\text {-stress }}$ decreases with $\mathrm{K}_{\mathrm{I}}$. $\mathrm{Q}_{\text {-stress }}$ generally decreases with applied loading for both deep crack and shallow crack cases. $Q_{\text {-stress }}$ is negative, meaning a deviation from HRR field. By comparing Fig. 8 with Fig. 6 , it is seen that constraint of CT specimens is much higher than that of SEB specimen. However, for the SEB specimen with deep crack, no constraint loss occurs in the linear elastic analysis. $\mathrm{Q}_{\text {-stress }}$ decreases with the applied loading and shows negative values at some points. This means the loss of constraint and raises the question whether it is conservative to obtain fracture toughness from SEB

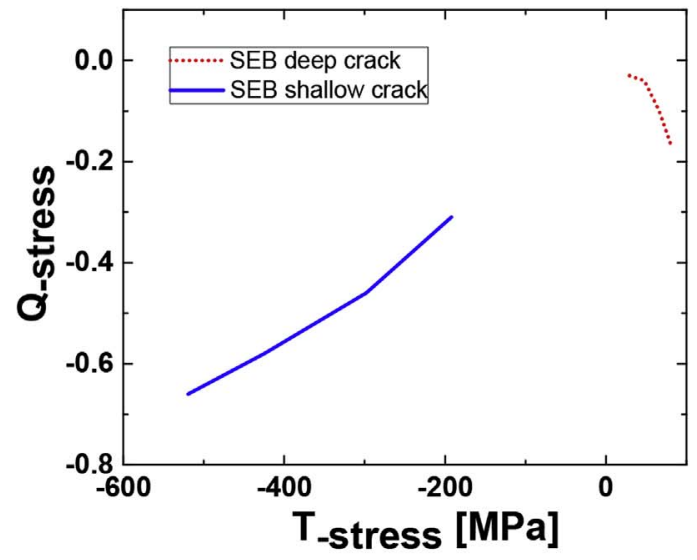

(a)

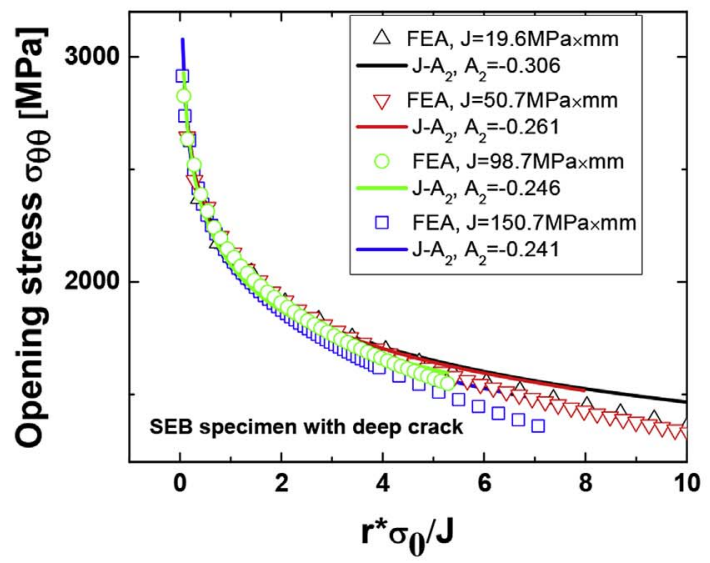

(b)

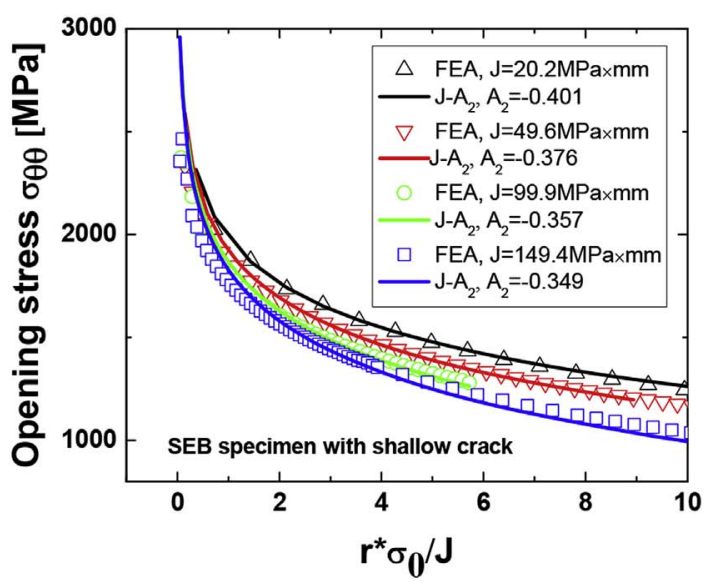

(c)

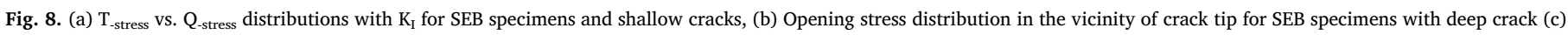
Opening stress distribution in the vicinity of crack tip for SEB specimens with shallow crack. 
specimens.

Fig. 8 (b) and (c) show the opening stress distributions of the deep and shallow cracked SEB specimens at different loading levels J. The results from the FE analysis and the $\mathrm{J}-\mathrm{A}_{2}$ solution with the calibrated $\mathrm{A}_{2}$ parameters are compared. It demonstrates that, for both the deep and shallow cracked SEB specimens, the $\mathrm{J}_{-} \mathrm{A}_{2}$ solutions agrees very well with the results from the $\mathrm{FE}$ analysis along the radial direction within the range of $\mathrm{r} /\left(\mathrm{J} / \sigma_{0}\right)=1-5$.

$\mathrm{J}-\mathrm{A}_{2}$ method is further used to quantify the constraint effect in the elastic-plastic analysis, as shown in Fig. 9. J-integral increases along the crack front from surface to the deepest point. The surface point has a more negative $A_{2}$ than the deepest point, which indicates that the surface point has a lower constraint than the deepest point of the crack front.

\subsection{Results from CRB specimen}

$\mathrm{K}_{\mathrm{I}}$ and $\mathrm{T}_{\text {-stress }}$ distributions along the crack front in the CRB specimen are shown in Fig. 10 (a). Crack tip angle $0^{\circ}$ means the surface of the crack and $90^{\circ}$ means the deepest point. $\mathrm{K}_{\mathrm{I}}$ generally increases from crack surface to the deepest, due to the increase of the crack depth. T. stress shows an opposite trend with $\mathrm{K}_{\mathrm{I}}$. As observed before, constraint depends on the applied loading. The surface point has a positive $\mathrm{T}_{\text {-stress }}$ while the deepest point has a loss of constraint. The variation of constraint requires a precise method to scale material toughness to the crack tip. In elastic-plastic analysis, variation of $\mathrm{Q}_{\text {-stress }}$ is shown in Fig. 10 (b).Generally, Q-stress shows negative values and loss of constraint occurs along the crack tip. In contrast to the elastic constraint analysis, the constraint at the crack tip surface shows a least constraint while the deepest point has a relatively higher constraint. The dependence of constraint on the location and loading is further confirmed. The crack tip stresses evaluated by the FE method and the J-A method are plotted in Fig. 10 (c), and good agreement is obtained.

$\mathrm{J}-\mathrm{A}_{2}$ method is further used to quantify the constraint effect in the elastic-plastic analysis. In agreement with the elastic analysis shown in Fig. 10, J-integral increases along the crack front from surface to the deepest point, as shown in Fig. 11. The surface point has a more negative $A_{2}$ than the deepest point, which indicates that the surface point has a lower constraint than the deepest point of the crack front.

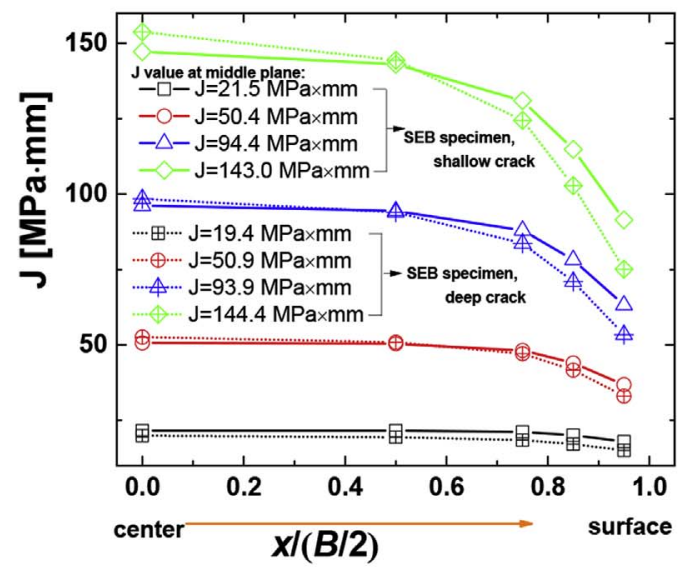

(a)

\section{Discussions}

\section{1. $J_{\text {eff }} / J$}

From the above results, it is seen that the fracture toughness in different specimens may vary due to the different constraints. Thus, a method to scale J-integral at different constraints is discussed in the following. From elastic-plastic fracture mechanics theory, the stress fields of the crack tip may be characterized by the classical HRR solution (Hutchinson, 1968) as

$\sigma_{\theta}=\sigma_{0}\left(\frac{J}{\alpha \varepsilon_{0} \sigma_{0} I_{n} r}\right)^{1 / n+1} \widetilde{\sigma}_{i j}(\theta, n)$

where $\sigma_{0}$ is a reference stress that is generally equal to the yield stress, $\varepsilon_{0}$ is defined as $\sigma_{0} / E$, and $E$ is the Young's modulus, $\alpha$ is material constant and $n$ is the strain hardening exponent, as given in the RambergOsgood stress-strain relationship (Eq. (8)), $I_{\mathrm{n}}$ is an integration constant that depends on $n$ and $\widetilde{\sigma}_{i j}(\theta, n)$ is the dimensionless function of $n$ and $\theta$.

To study the difference in the constraint state, the effective J-integral in the studied models is calculated. Here the effective J-integral is a J-integral in such HRR stress field that matches the stress field of the crack tip under the specific constraint conditions. Eq. (10), which indicates the crack tip stress field, can be expressed by using $J_{\text {eff: }}$ :

$\sigma_{\theta}=\sigma_{0}\left(\frac{J_{e f f}}{\alpha \varepsilon_{0} \sigma_{0} I_{n} r}\right)^{1 / n+1} \widetilde{\sigma}_{i j}(\theta, n)$

By substituting Eq. (11) into Eq. (2), the ratio of $J_{\text {eff }}$ to the $J$-integral can be expressed by

$\frac{J_{\text {eff }}}{J}=\left(1+\frac{Q_{\text {stress }}}{\left(E / \alpha \sigma_{0} I_{n} r\right)^{1 / n+1} \widetilde{\sigma}_{i j}(\theta, n)}\right)^{n+1}$

Fig. 12 shows $\mathrm{J}_{\text {eff }} / \mathrm{J}$ for the CT specimen, SEB specimen and CRB specimen. Since the CT specimen has a highest constraint, $\mathrm{J}_{\text {eff }} / \mathrm{J}$ is higher than that of the other specimens. CRB specimen has a constraint between SEB specimen with shallow and deep crack. $J_{\text {eff }}$ of the cruciform specimen subjected to biaxial loading is about $2-15 \%$ smaller than that of the CT specimen. This result can be used to scale fracture toughness between different specimens.

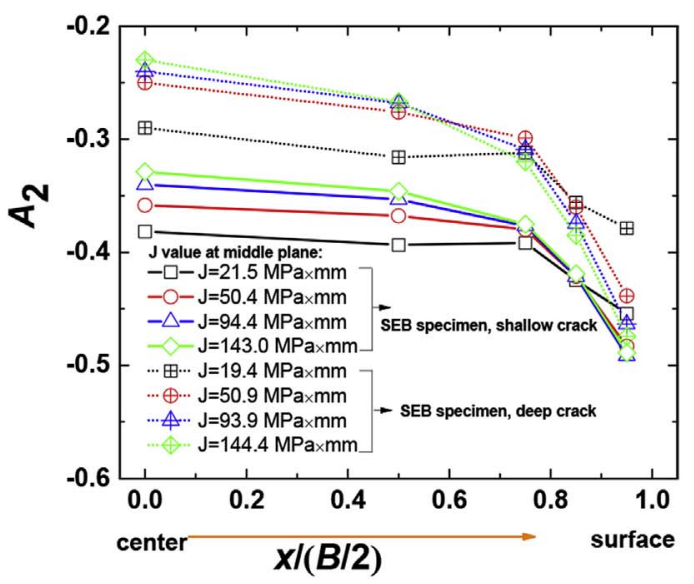

(b)

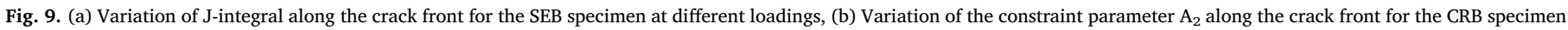
at different loadings. 


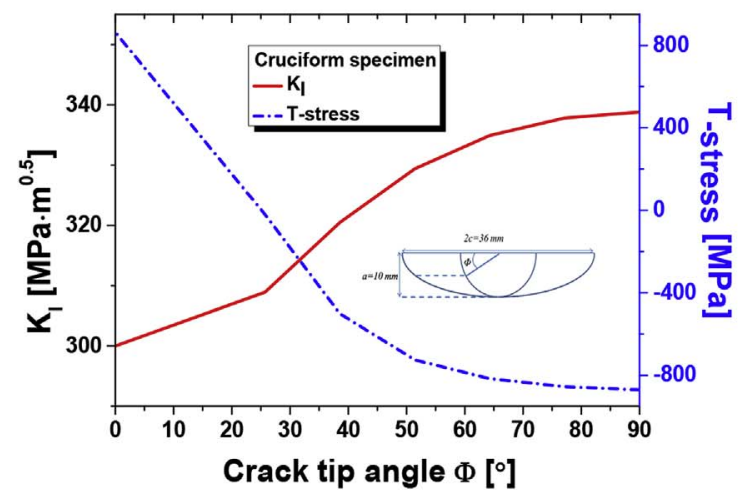

(a)

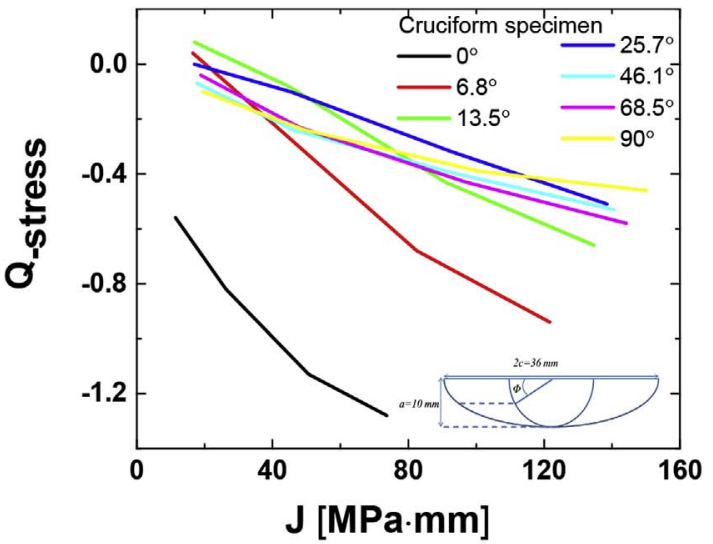

(b)

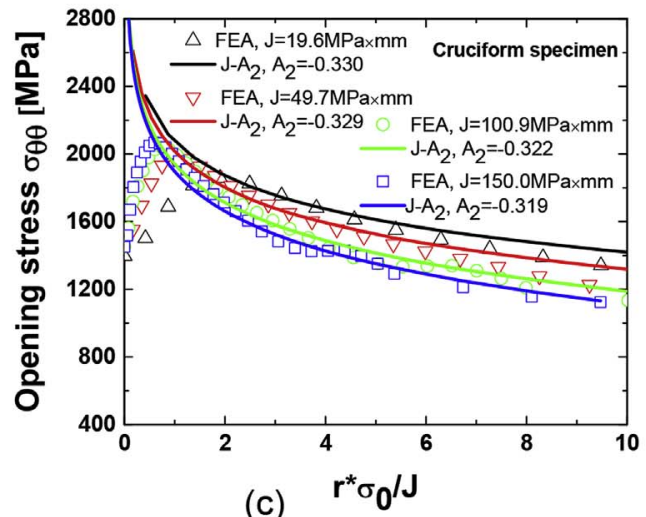

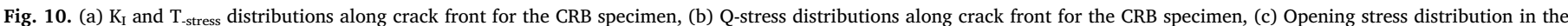
vicinity of crack tip for the CRB specimen at different loadings.

\subsection{Fracture probability for different specimens}

Moreover, the modified Beremin model (Eq. (7)) is used to scale fracture toughness in different specimens. According to the European program (Hümmer et al., 2007), the calibrated parameters for this RPV material are $\mathrm{m}=6.36, \quad \sigma_{\mathrm{th}}=1546 \mathrm{MPa}, \quad \sigma_{\mathrm{u}}=2076 \mathrm{MPa}$, $\mathrm{V}_{0}=0.001 \mathrm{~mm}^{3}$. The integration zone is the volume where the von Mises stress is over two times the yielding stress. Fig. 13 (a) shows the

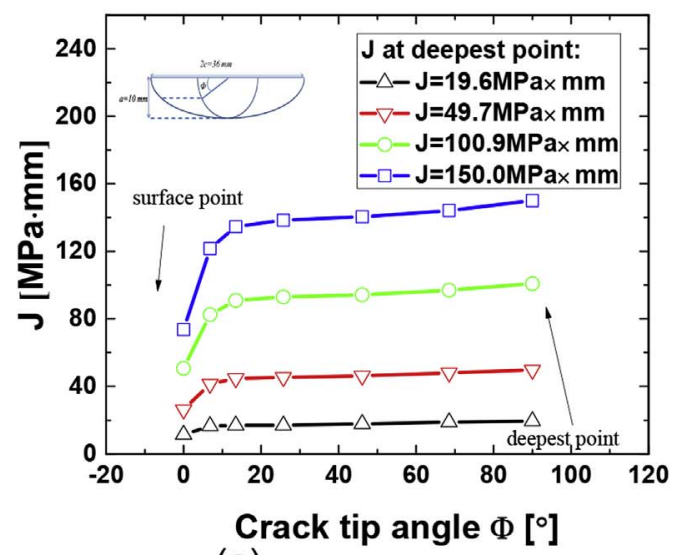

(a)
Weibull stresses $\left(\sigma_{\mathrm{w}}\right)$ of the CT, SEB, CRB specimen and MBL model as a function of $\mathrm{K}_{\mathrm{J}}$. The cruciform specimen subjected to uniaxial loading is also modeled and the corresponding $\sigma_{\mathrm{w}}$ and $\mathrm{P}_{\mathrm{f}}$ are calculated. It is indicated that the Weibull stresses $\sigma_{\mathrm{w}}$ for the MBL model is greater than that for the CT specimen and SEB specimen. $\sigma_{\mathrm{w}}$ for the SEB specimen with deep crack are greater that with shallow crack. $\sigma_{\mathrm{w}}$ captures the constraint effect due to the different stress distributions at the same J.

An important objective of the constraint analysis is to estimate the

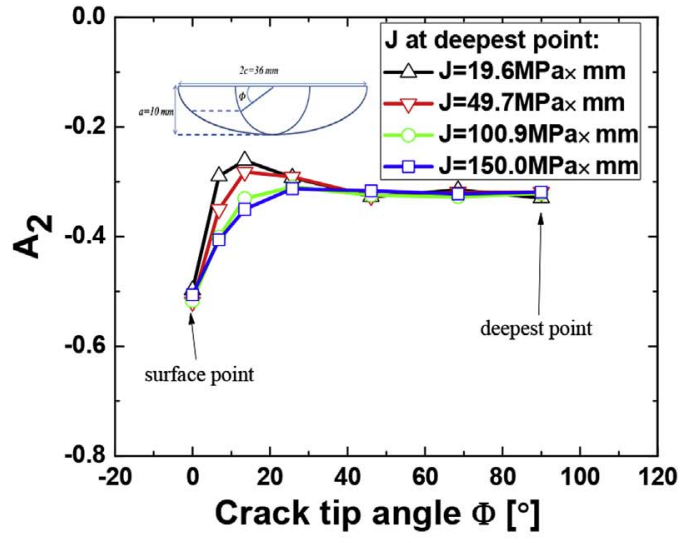

(b)

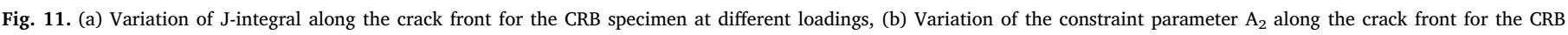
specimen at different loadings. 


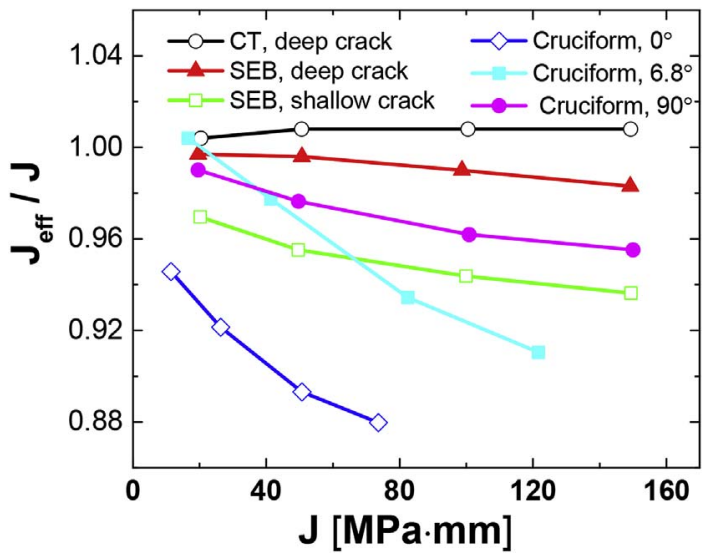

Fig. 12. Comparison of $J_{\text {eff }} / J$ for CT specimen, SEB specimen, MBL model with deep and shallow cracks at different loadings.

probabilities of cleavage initiation for different specimens and components. Therefore, it is necessary to calculate the fracture probability $\left(\mathrm{P}_{\mathrm{f}}\right)$ for different specimens. In order to decide which specimen fails first during the loading, it is better to compare $\mathrm{P}_{\mathrm{f}}$ for the same J-Integral. It is clear in Fig. 13 (b) that the MBL model fails first, followed by CT specimen, SEB specimen and cruciform specimen. The results in Fig. 13 may be used to scale fracture toughness data to account for both inplane and out-of-plane constraint effect by indexing a given $\mathrm{P}_{\mathrm{f}}$ for a specific constraint to obtain $\mathrm{J}$. At a fracture probability of $10 \%$, the fracture toughness difference between CT specimen and CRB specimen is about $50 \mathrm{MPa} \mathrm{m}^{0.5}$, i.e $200 \%$ of the material toughness. The difference between SEB and CT specimen is $28 \mathrm{MPa} \mathrm{m}^{0.5}$ (107\% of the material toughness). This big difference demonstrates the importance of considering the constraint effects in the integrity analysis.

\subsection{Material failure curve}

In the following, a comparison of material failure curve and crack driving force curves for CT, SEB specimen, MBL model at different loadings is presented based on the $\mathrm{J}_{-} \mathrm{A}_{2}$ method. The material failure curve is developed by plotting J-integral versus the absolute value of $A_{2}$ at different loadings. The critical stress for fracture $\left(\sigma_{\mathrm{c}}\right)$ and the corresponding critical radial distance $\left(r_{\mathrm{c}}\right)$ from the RKR model (Ritchie et al., 1973) are substituted into Eq. (3), as

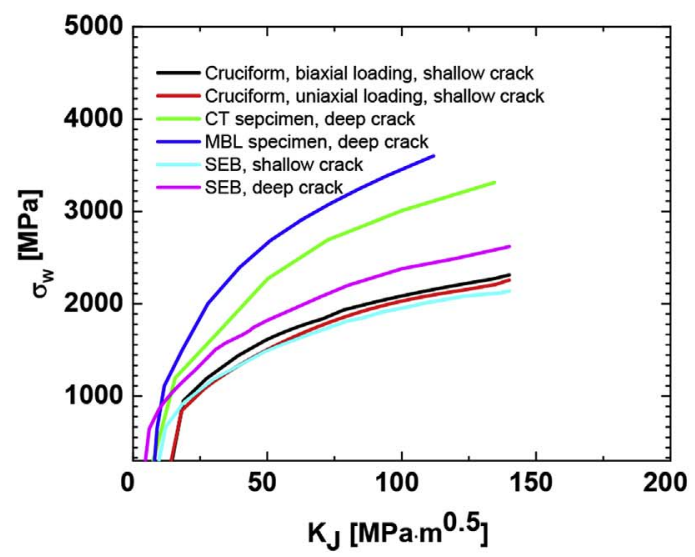

(a)

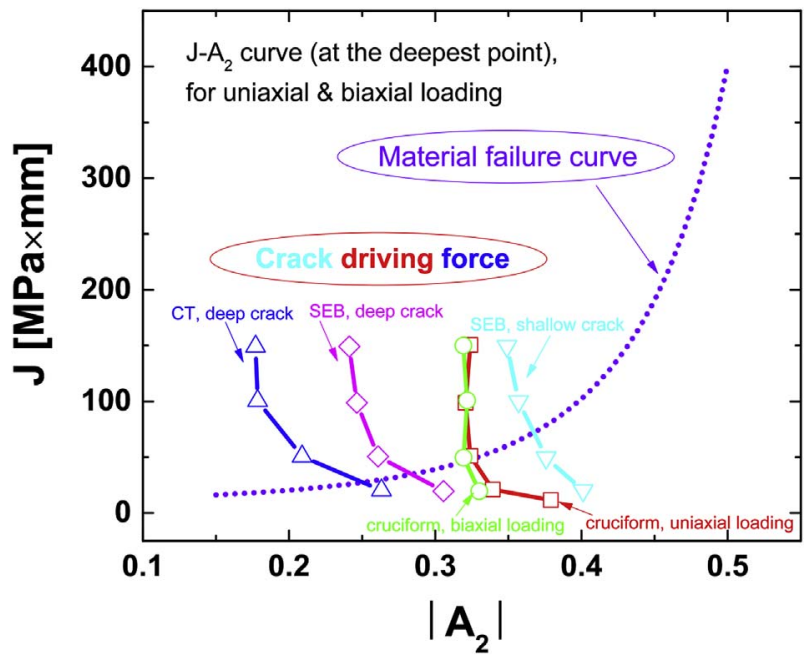

Fig. 14. Comparison of material failure curve and crack driving force curves for CT, SEB specimen, MBL model with deep and shallow cracks at different loadings.

$\frac{\sigma_{c}}{\sigma_{0}}=A_{1}\left[\left(\frac{r_{c}}{L}\right)^{s_{1}} \widetilde{\sigma}_{i j}^{1}(\theta, n)+A_{2}\left(\frac{r_{c}}{L}\right)^{s_{2}} \widetilde{\sigma}_{i j}^{2}(\theta, n)+A_{2}^{2}\left(\frac{r_{c}}{L}\right)^{s_{3}} \widetilde{\sigma}_{i j}^{3}(\theta, n)\right]$

Eqs. (3) and (13) are used to plot the crack driving force curve and the material failure curve according to the following procedure: (1) Obtain the opening stress distribution $\sigma_{\theta \theta}$ at a point of interest along the crack front from the FE analysis at the load level $J_{\mathrm{c}}$. Substitute $J_{\mathrm{c}}, \sigma_{\theta \theta}$, and $r$ into Eq. (3) to solve for $A_{2}$ at each node. The average $A_{2}$ value in the range of $r /\left(J / \sigma_{0}\right)=2-5, \theta=0^{\circ}$ is taken as the $\left(J_{\mathrm{c}}, \mathrm{A}_{2}\right)$ pair for the specimen. These pairs of $\left(J_{\mathrm{c}}, \mathrm{A}_{2}\right)$ are the crack driving force for different specimens. (2) In order to plot the material failure curve, $A_{2}$ in Eq. (3) is firstly calibrated based on CT specimen at different $\mathrm{J}$. In this paper, $\sigma_{\mathrm{c}}=1830 \mathrm{MPa}$ is then taken as the fracture stress (Ritchie et al., 1973) and is substituted into Eq. (13) to calculate the $r_{\mathrm{c}}$. Lastly, $\sigma_{\mathrm{c}}$ and $r_{\mathrm{c}}$ are substituted back to Eq. (13) to obtain $\mathrm{J}$ at an arbitrary $A_{2}$. These $\left(J, A_{2}\right)$ pairs are the material failure curve. In this way, both the crack driving force and material failure curve are plotted in Fig. 14. The intersection points between the material failure curve and crack driving force are the critical points, above which cleavage fracture occurs. It is seen at some critical J-integral, CT specimen fails first while SEB specimen with shallow crack fails last due to different constraint.

Fig. 14 also compares the constraint differences among the specimens investigated. The lower the intersection point between the failure

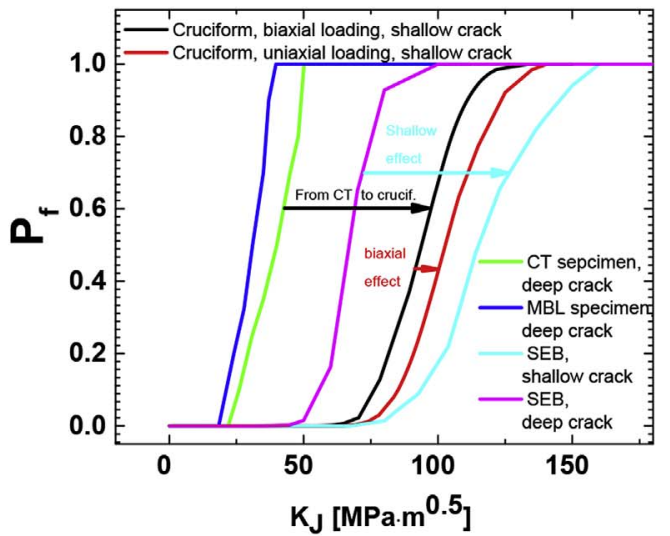

(b)

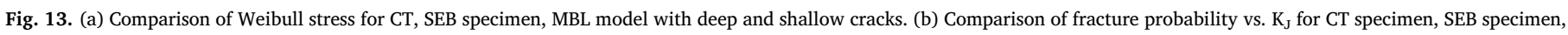
MBL model with deep and shallow cracks. 


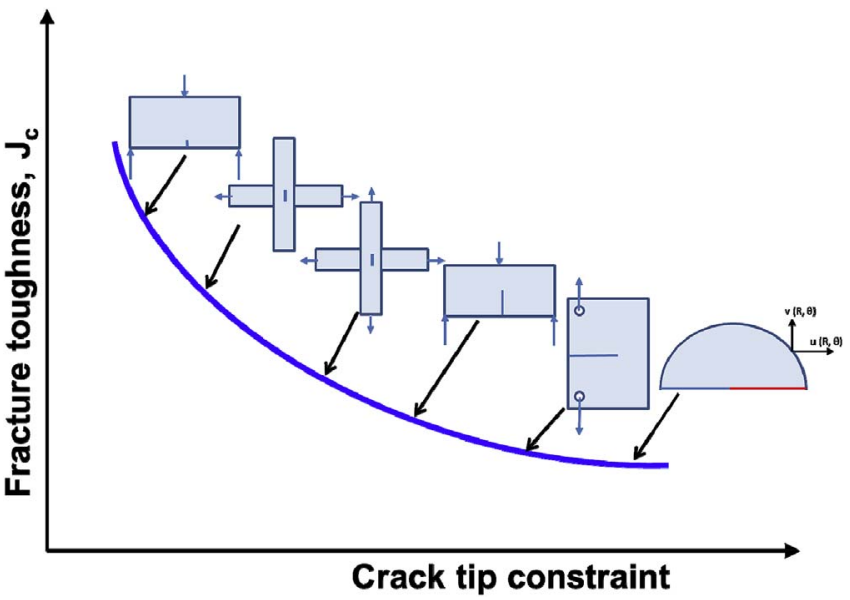

Fig. 15. Comparison of constraints for different specimens and structures, based on elastic-plastic analysis.

curve and crack driving force is, the higher constraint the specimen exhibits. Therefore, the CT specimen has the highest constraint while the SEB specimen with a shallow crack has the lowest constraint level. The cruciform specimen under biaxial and uniaxial loading investigated in this study has the constraint level between the SEB specimens with deep and shallow cracks. The constraint of the cruciform specimen under uniaxial loading is lower than that of the same type of specimen under biaxial loading. It is noted that in Fig. 14 the resulting critical $\mathrm{J}$ is rather insensitive to the $\mathrm{A}_{2}$. The value of $\mathrm{A} 2$ becomes a constant as the applied load increases which results in the large scale yielding condition near the crack tip. This is proved and explained in (Chao et al., 1994).

\subsection{Comparison of constraints}

In the preceding study, the constraints in different specimens are studied. Both elastic and elastic-plastic analyses are performed. From the study in Section 4.2, SEB deep crack model would possess higher elastic constraint than the MBL model which has zero T stress. However, from elastic-plastic analysis, as shown in Fig. 13 a and b, MBL model has a higher Weibull stress and failure probability at the same KJ. This implies that the MBL model has a higher elastic-plastic constraint than the SEB model with deep crack. This confirms that the elastic constraint may be different from elastic-plastic constraint. The following Fig. 15 is based on the results from elastic-plastic analysis. It is found that MBL model has a highest constraint, followed by CT specimen, SEB specimen with deep crack, SEB specimen with shallow crack. CRB specimen with shallow crack has the lowest constraint and thus demonstrates the highest apparent fracture toughness. A qualitative comparison of the crack tip constraint and fracture toughness in different specimens is shown in Fig. 15. It would be conservative to apply the fracture toughness obtained from CT or SEB specimen with deep cracks to a RPV subjected to biaxial loading. In the transferring of material toughness from different specimens and structures, the effective $J_{\text {eff }}$ and local approach to fracture mechanics can be employed based on elastic-plastic analysis.

\section{Conclusions}

This paper is dedicated to the comparison of the difference in crack tip constraint for cruciform specimen with shallow crack, compact tension specimen and three point bending specimen with shallow and deep cracks. Both linear elastic and elastic-plastic fracture mechanics are applied to study the constraint effect based on two-parameter fracture criterion. Based on the analyses, the following conclusions are drawn:
(1) The constraint is dependent on loading and specimen geometry. Elastic constraint is different from the constraint in elastic-plastic analysis. Along a curved crack front, the constraint shows a continuous variation. In case of positive $\mathrm{T}_{\text {-stress }}, \mathrm{T}_{\text {-stress }}$ increases with $\mathrm{K}_{\mathrm{I}}$. In the case of negative $\mathrm{T}_{\text {-stress }}, \mathrm{T}_{\text {-stress }}$ decreases with $\mathrm{K}_{\mathrm{I}}$. $\mathrm{Q}_{\text {-stress }}$ generally decreases with applied loading for both deep crack and shallow crack cases. Loss of constraint occurs for the SEB specimen with deep crack and thus raises the question whether the SEB specimen is proper to be used to obtain material toughness. For the CRB specimen, the constraint at the crack tip surface shows a least constraint while the deepest point has a relatively higher constraint.

(2) $\mathrm{J}_{-} \mathrm{A}_{2}$ method is used to precisely capture the crack tip constraint and crack tip stress distributions. Crack driving force and material failure curve for different specimens are well described by the $\mathrm{J}-\mathrm{A}_{2}$ method. The effective J-integral of the cruciform specimen subjected to biaxial loading is about $2-15 \%$ smaller than that of the CT specimen. Fracture toughness values obtained from the CT specimen with higher constraint effects are on the conservative side.

(3) The CT specimen has the highest constraint while the SEB specimen with a shallow crack has the lowest constraint level. The cruciform specimen under biaxial and uniaxial loading investigated in this study has the constraint level between the SEB specimens with deep and shallow cracks. The constraint of the cruciform specimen under uniaxial loading is lower than that of the same type of specimen under biaxial loading.

(4) Weibull stress can be applied to transfer the fracture toughness among different specimens at the same failure probability. At a fracture probability of $10 \%$, the fracture toughness difference between the CT specimen and CRB specimen is about $200 \%$ of the material toughness, which demonstrates the importance of considering the constraint effects in the integrity analysis.

\section{Acknowledgements}

Guian Qian and Markus Niffenegger are grateful for the financial support of the PROBAB Project provided by the Swiss Federal Nuclear Safety Inspectorate (ENSI) (DIS-Vertrag Nr. H-100668).

\section{References}

Abaqus 6.14 Manual, Version 6.14, Hibbitt, Karlsson \& Sorensen, Inc., 2017. ASTM E399-09e2, 2011. Standard Test Method for Linear-elastic Plane Strain Fracture Toughness $\mathrm{K}_{\mathrm{Ic}}$ of Metallic Materials. American Society for Testing and Materials.

Bass, B.R., et al., 1999. Fracture assessment of shallow-flaw cruciform beams tested under uniaxial and biaxial loading conditions. Nucl. Eng. Des. 188 (3), 259-288.

Beremin, F., 1983. A local criterion for cleavage fracture of a nuclear pressure vessel steel. Metall Trans A 14A, 2277-2287.

Chao, Y.J., Yang, S., Sutton, M.A., 1994. On the fracture of solids characterized by one or two parameters: theory and practice. J. Mech. Phys. Solid. 42 (4), 629-647.

Faleskog, J., 1995. Effects of local constraint along three-dimensional crack fronts-a numerical and experimental investigation. J. Mech. Phys. Solid. 43 (3), 447-493.

Gao, X., Zhang, G., Srivatsan, T.S., 2005. Prediction of cleavage fracture in ferritic steels: a modified Weibull stress model. Mater. Sci. Eng. A 394, 210-219.

Guo, W., 1993. Elastoplastic three dimensional crack border field-I. Singular structure of the field. Eng. Fract. Mech. 46 (1), 93-104.

Hancock, J.W., Du, Z.Z., 1991. Two parameters characterization of elastic-plastic cracktip fields. ASME J. Appl. Mech 113, 104-110.

Hohe, J., et al., 2011. Enhanced fracture assessment under biaxial external loads using small scale cruciform bending specimens. Eng. Fract. Mech. 78 (9), 1876-1894.

Hümmer, M., Keim, E., Hofmann H. Times., An international project on transferability of fracture toughness values for irradiated RPV steels, Proceedings of the PVP, July 2226, 2007 ASME Pressure Vessels and Piping Division Conference, San Antonio, Texas, USA.

Hutchinson, J.W., 1968. Singular behaviour at the end of a tensile crack in a hardening material. J. Mech. Phys. Solid. 16 (1), 13-31.

Joyce, J., Link, R., Gaies, J., 2005. Evaluation of the effect of Biaxial loading on the to reference temperature using a Cruciform Specimen Geometry. J. ASTM Int. 2 (1), $1-18$.

Link, R.E., Joyce, J.A., Roe, C., 2007. An experimental investigation of the effect of biaxial loading on the master curve transition temperature in RPV steels. Eng. Fract. Mech. 74 (17), 2824-2843.

Matvienko, Y.G., Shlyannikov, V.N., Boychenko, N.V., 2013. In-plane and out-of-plane constraint parameters along a three-dimensional crack-front stress field under creep 
loading. Fatig. Fract. Eng. Mater. Struct. 36 (1), 14-24.

O'Dowd, N., Shih, C., 1991. Family of crack-tip fields characterized by a triaxiality parameter - I. Structure of fields. J. Mech. Phys. Solid. 39, 989-1015.

Qian, G., Niffenegger, M., 2013. Integrity analysis of a reactor pressure vessel subjected to pressurized thermal shocks by considering constraint effect. Eng. Fract. Mech. $112-113,14-25$.

Qian, G., Niffenegger, M., 2015. Investigation of constraint and warm prestressing effects by means of a local approach to fracture. Eng. Fract. Mech. 136, 26-37.

Qian, G., Gonzalez-Albuixech, V.F., Niffenegger, M., 2014. In-plane and out-of-plane constraint effects under pressurized thermal shocks. Int. J. Solid Struct. 51, 1311-1321.
Ritchie, R.O., Knott, J.F., Rice, J.R., 1973. On the relationship between critical tensile stress and fracture toughness in mild steel. J. Mech. Phys. Solid. 21, 395-410.

Williams, M., 1957. On the stress distribution at the base of a stationary crack. ASME J Appl Mech 24, 109-114.

Yang, S., Chao, Y.J., Sutton, M.A., 1993a. Complete theoretical analysis for higher order asymptotic terms and the HRR zone at a crack tip for Mode I and Mode II loading of a hardening material. Acta Mechanica 98 (1), 79-98.

Yang, S., Chao, Y.J., Sutton, M.A., 1993b. Higher order asymptotic crack tip fields in a power-law hardening material. Eng. Fract. Mech. 45 (1), 1-20.

Zhu, X.K., Joyce, J.A., 2012. Review of fracture toughness (G, K, J, CTOD, CTOA) testing and standardization. Eng. Fract. Mech. 85, 1-46. 